\title{
SUPERAR LA HYBRIS DEL HUMANISMO. TESIS PARA UN POSTHUMANISMO DE LA KÉNOSIS DESPUÉS DE HEIDEGGER*
}

\author{
José Manuel Chillón Lorenzo** \\ josemanuel@fyl.uva.es
}

RESUMEN Frente a la hybris de la subjetividad que culmina en el proyecto moderno-humanista, surge la necesidad de pensar de otra manera la esencia del hombre ya sin el lastre de toda la tradición filosófica occidental. Este viraje que Heidegger imprime al pensar se explica aquí desde lo que denomino tesis para la reconstrucción de un posthumanismo en la perspectiva de la kénosis y que se resume en: la superación de las leyes de la gramática y el acento en el decir poético; el reconocimiento del mientras tanto de la existencia humana finita siempre en camino; $y$, por último, el preciso abajamiento del pensar tal y como corresponde no y a la incontestable potestad del señor del ente sino a la esencial pobreza del pastor.

Palabras clave Humanismo, Heidegger, Kénosis, posthumanismo, verdad del ser, pensar.

ABSTRACT Before the hybris of subjectivity that culminates in the modern-humanist project, there arises the need to think the essence of man, in another way, a way already without the burden of the entire western philosophical tradition. This turn that Heidegger gives to thinking is here explained from what I call: thesis for the reconstruction of post-humanism in the perspective of kenosis, which can be summarized as overcoming the laws of grammar and

* Este artículo se enmarca dentro del Proyecto de Investigación del MINECO del Estado Español sobre la trascendentalidad de la fenomenología cuya referencia es FF12015-63794-P. Artículo sometido el 12/09/2017. Aceptado el 10/12/2017.

** Universidad de Valladolid, Valladolid, España. 
accent in the poetic saying, recognition of a meanwhile of the finite human existence always on its way and, finally, the precise reduction of thinking as it corresponds not to the power of the lord of the being but to the essential shepherd's poverty.

Keywords Humanism, Heidegger's kénosis, posthumanism, truth of being, thinking.

\section{La superación del humanismo y la época postmetafísica}

Ninguna de las realidades empíricas sirve de fundamento ni otorga la ultimidad que busca la fenomenología. ¿Es el hombre acaso una realidad empírica sin más? Es evidente que sí, al menos para la tradición humanista según el diagnóstico heideggeriano. Sin embargo, el ser humano no es un ente al uso. Curiosamente ha sido la insistencia en la consideración del homo como subiectum lo que ha reducido al propio ser humano a un objectum. Toda teoría sobre el hombre, todo antropologismo, es una manera de ocultar la esencia del ser humano porque, como positivismo que es, acaba cayendo en las sutiles arenas movedizas del nihilismo que impide pensar el ser a fuerza de insistir solo en el ente. De esto va, en mi opinión, la "Carta sobre el humanismo"1 al perfilar una dirección filosófica que se barruntaba ya en los escritos de la llamada 'década fenomenológica' (1919-1929): la filosofía no puede contar con el hombre sino en su servir al ser a cuya luz solo se puede pensar la esencia (y por lo tanto la dignidad) de este ente que es el ser humano con el que la filosofía no puede comprometerse en decir otra cosa que no sea 'Dasein', ${ }^{2}$ asumiendo así que lo propio del ser humano es su 'ek-sistencia' en cuanto 'seren-el-mundo'. 'Dasein' es pues el nombre para la experiencia primaria de lo humano a la que ha de referirse la fenomenología hermenéutica en ese esfuerzo por acceder al ámbito de lo más fundamental y preteórico, al fundamento previo a poder hablar del ilustrado concepto de 'individuum', 'subjectum',

1 "En este escrito, que formalmente quería ser una carta, pone al descubierto las condiciones del humanismo europeo y las somete a preguntas que exceden tales condiciones entrando en un espacio de pensamiento transhumanístico o posthumanístico en el que desde entonces se viene moviendo una parte esencial de la reflexión filosófica sobre el hombre" (Sloterdijk 2011, p. 204).

2 El 'Dasein', explica Félix Duque (2006, p. 50), no es una mera abstracción del hombre sino, al contrario, aquella expresión que revela toda manera humana de ser fácticamente. Siguiendo las lecciones de Heidegger de 1928 (GA26, Metaphysische Anfangsgründe der Logik im Ausgang von Leibniz) en la que se distingue cuidadosamente entre 'Dasein' y 'Mensch', Heidegger define el 'Dasein' como una tarea, como una tensión más que como una cosa o una sustancia. De este modo, en mi opinión, el posthumanismo nace como consecuencia de esta operación de desustancialización de la subjetividad. 
'homo', 'Mensch' o incluso 'superhombre' (Heidegger, 1989, pp. 312-326)³ a la experiencia previa a la determinación de la subjetividad productora de los entes y dominadora de la naturaleza que, al final, resulta sometida a su omnímodo poder como ha podido comprobarse en la era tecnológica. Todos estos conceptos agrupados en las grandes concepciones sobre el hombre no han logrado resolver la catástrofe en la que ha vivido inmerso el siglo XX. El problema es el hombre, efectivamente. Pero la solución no puede estar en las teorías sobre el hombre que, de una manera u otra, impiden pensar (con la radicalidad que exigen estos tiempos convulsos) la esencia del ser humano. Y es que todas esas teorías participan de la conmoción que caracteriza el actual instante del mundo. Pensar de otra manera (en la que el pensar abrigue la esencia del ser humano) exige que causen baja los conceptos con los que la antropología, en cuanto delegada de la metafísica, ha pensado al hombre. El humanismo es, como mucho, una teoría sobre el hombre, pero una teoría que asume demasiados compromisos como para no ser advertidos por la fenomenología.

Lo original del asunto es que este enfrentamiento con el humanismo no le hace caer a Heidegger en los derroteros antihumanistas, en los caminos transitados por quienes han declarado el fin del antropocentrismo inaugurando un nihilismo tan problemático como el humanismo con el que está en liza. A favor o en contra del humanismo, la filosofía sigue instalada en la misma estructura del pensar y, de alguna manera, en la misma patología de la razón que, al final, va en contra del hombre que trataba de enaltecer. El pensar que postula Heidegger, sin embargo, es el pensar que vuelve a la esencia del hombre, es el pensar que sale de los márgenes del pensar representativo para pensar de otra manera eso que el pensar metafísico-tradicional mantuvo en el olvido. El mismo olvido del 'olvido del ser' de la metafísica occidental explica ahora el desapercibimiento que la esencia humana tuvo para un filosofar que convirtió al hombre en señor del ente, en un autómata sin necesidad de 'lo salvo' pero, a su vez, en otra cosa más sobre la que pensar y sobre la que enseñorearse.

El humanismo es incapaz de pensar cómo convoca el ser al hombre ${ }^{4}$. Sin albergar al ser, el pensar queda enredado en los entes. ${ }^{5} \mathrm{Y}$ así, confundido el

3 Según Heidegger el 'superhombre' de Zaratustra no es más que el mero ejercicio del poder de la voluntad de poder. (Heidegger 2013, p. 304)

4 Me parece muy sugerente la interpretación de Jacinto Choza sobre el dejarse interpelar del hombre por el ser en términos de enamoramiento. "Una persona que nunca se ha enamorado es una persona que nunca ha sido convocada por nadie a ser sí misma" (Choza, 2004, p. 40).

5 En palabras de Löwith (2006, p. 333): "El ser aparecerá precisamente en el volverse nulo de todo ente". 
hombre entre las cosas, solo puede pensar su esencia desde el prisma óntico que impide pensar el ser. El problema del humanismo es que en su territorio no ha lugar el pensar de la relación hombre y ser en otros términos que no sean el dominio, la calculabilidad, la productividad... criterios todos ante los que el ser no solo permanece oculto, sino que resulta imposible poder rememorar el olvido como la forma en la que el ser ha querido presentarse. El principio de razón suficiente (que se agota en la interpretación de los entes desfigurando así el problema del ser) es el presupuesto de todo comportamiento calculable en el que el hombre -según explica Heidegger en Der Satz vom Grund- es el viviente calculador ('das rechnende Lebewessen') cuyo pensar ha declinado en la actual 'era atómica'.

El posthumanismo, entonces, solo puede entenderse en el contexto postmetafísico y postfilosófico que Heidegger ha definido como "el final de la filosofía y el inicio del pensar". Y la cuestión capital tiene ahora que ver con qué se entiende con el prefijo 'post'. Según lo voy a plantear aquí, tal prefijo no significa sólo 'después de' en el sentido cronológico o 'más allá de' en el sentido de superioridad, sino que remite a la noción de superación que, siguiendo la propia concepción del pensar de Heidegger refiere a la necesidad de regenerar lo que la tradición ha contaminado y, por lo tanto, a la exigencia de no dar por supuestos los fundamentos aparentemente incólumes sobre los que se asienta, sino a volver a pensarlos en su origen: "La liberación de la tradición es la apropiación constantemente nueva de sus fuerzas reconocidas" (Heidegger, 2017, p. 417). Todo 'post-' obliga al pensar no tanto a ir más allá cuanto a volver más acá hacia lo que, por cercano, se presenta como lo más lejano; hacia lo que, por ya siempre dado, pasa por lo más desconocido. $\mathrm{Y}$ en esa tarea, no se trata de innovar, de pensar mejor, sino de repetir, de volver a pensar lo que el pensar lógico dejó sin pensar. Pensar el hombre es pensar contra el humanismo no para caer en un antihumanismo degradante y nihilista sino para "poner la dignidad humana a la altura que le corresponde" (Heidegger, 2016, p. 42). Esa altura no es ni mucho menos la altura de la comprensión subjetiva del hombre en forma de autoconciencia por la que el ser del ente queda oculto tras el velo de la objetividad sobre la que el sujeto alza su poder. La altura de la dignidad humana debe volver a ser pensada ya no desde la 'hybris' del poder de la subjetividad para con los entes y para con el propio ser humano (fundamento teórico de la técnica moderna), sino desde un abajamiento en perspectiva 'kenótica' en la que el pensar accede al hombre en una dependencia ontológica que le hace oyente del ser en el que 'ek-siste' y servidor de la verdad del ser, más que constructor a su modo de los conceptos con los que resultan sometidos los entes. 
La 'hybris' humana ha perdido por completo la posibilidad de que el hombre pueda descubrirse estando en la verdad del ser. Aquella prepotencia humana provoca el desterramiento por el que el hombre vaga sin patria ('Heimat'), sin experimentar la proximidad del ser y es ahí donde se barrunta ya el olvido del ser: en el hecho de que el hombre siempre vuelve al ente para quedar enredado en él. El pensar que supera la metafísica no es 'post-' por sobrepasarla sino por volver a descender "a la proximidad de lo más próximo" (Heidegger, 2016, p. 76). Y, como advierte Heidegger, el descenso es más que peligroso por desenfrenado debido al efecto rebote del pensar del ascenso (propio de la subjetividad) que se ha estrellado. ¿En qué se puede advertir ese haberse estrellado? En que la promesa de la época de la dominación sobre todas las cosas se ha vuelto contra el propio hombre provocando, en el actual instante del mundo, "la conmoción de todo lo ente" (Heidegger, 2016, p. 78). Pensar la esencia del hombre exige el abajamiento del pensar que desciende hacia la pobreza de la 'ek-sistencia'. A esto quiero referirme con el posthumanismo kenótico.

\section{Posthumanismo y memoria del olvido del ser. Sobre la "Carta sobre el humanismo"}

La cuestión del ser no puede plantearse, en palabras de Blumenberg (2011, p. 13), en otro sitio que no sea el hombre. Por eso, el posthumanismo debe contextualizarse en el marco del pensar del ser, en los dos posibles sentidos del genitivo. “¿Qué es el hombre que en el fondo de su esencia filosofa?”, se pregunta Heidegger (2017, p. 27). Y es que la pregunta por el ser que convoca al hombre no es una pregunta más que el hombre pudiera no hacerse, sino la pregunta que le constituye como aquel ente ocupado por el ser en cuya pregunta "le va su propio ser". ${ }^{6}$ En ese sentido, la esencia de la filosofía y la esencia del hombre están profundamente implicadas. Y entonces, la filosofía, más que alharacas científicas y pronunciamientos sabios, es pensamiento último y silencioso, conversación a solas del hombre o, en palabras de Zubiri, 'soledad sonora'. Y, evidentemente, al acontecer la filosofía no como una ocupación cualquiera sino como lo que sucede en el fondo de la existencia, como lo que afecta a la 'existencia toda' que diría Husserl, no hay teoría que

6 Por cierto, con claras resonancias de las Confesiones agustinianas (Conf. en adelante): "mihi quaestio factus sum" (Conf. X, 33). Tanto Agustín como Heidegger -explica Grondin- coinciden en situar lo genuino de la existencia humana en su capacidad para preguntar. Una existencia que, fenomenológicamente descrita y fácticamente considerada, resulta precisamente estructurada por la pregunta (Grondin, 2010, pp. 150-172). 
pueda agotarla. La verdad de la filosofía "es esencialmente la verdad de la existencia humana" (Heidegger, 2017, p. 43). De una filosofía epistemológica fundamentalmente preocupada por cómo el sujeto puede hacerse con el objeto deviene una idea de hombre que, fundada en la subjetividad, termina considerándolo como señor y dominador del ente. Pero esta otra forma de pensar que se postula advierte, a su vez, de la necesidad de pensar la esencia humana que ha sido avasallada por las construcciones modernas. La filosofía de este pensar postfilosófico pone la existencia misma en juego, algo que no había hecho ninguna filosofía, ni siquiera la de Descartes por mucho que la apariencia de la duda parezca hacer de la filosofía resultante una crítica que, en realidad, no es ni vinculante ni peligrosa. La 'humanitas' del hombre acontece como problema filosófico cuando preguntamos por nosotros mismos que, como hombres, "tenemos encomendada la tarea de serlo". De modo que, sólo la disposición para la pregunta por el ser del que pregunta (y, por lo tanto, el retorno a la sentencia inicial "conócete a ti mismo") se plantea correctamente desde "la entrega del hombre a su existencia que es el indicio de la interna finitud" (Heidegger, 2017, p. 339).

La tradición humanista pensó la esencia del hombre desde la animalidad con la diferencia específica de la posesión de la palabra. Pero como el humanismo se había fraguado en torno a la animalidad, el pensar metafísico occidental nunca pudo pensar al hombre desde su 'humanitas' sino desde su 'animalitas', siguiendo así en los márgenes del ente. Pero, según Heidegger, sólo puede pensarse la esencia del hombre como tal desde su 'ek-sistencia' determinada por su estar en la proximidad del ser. Una 'ek-sistencia' esta del ser humano que, en tanto configurador de mundo, 'deja ser' a los entes que le salen al encuentro. "A estar en el claro del ser es a lo que yo llamo la eksistencia del hombre" (Heidegger, 2016, p. 31). O lo que es lo mismo, si la proximidad del hombre al ser (Nähe zum Sein) es la que determina la dignidad del ser humano, su lejanía, su expulsión del claro del ser, le hace girar sobre sí mismo como 'animale rationale'.

En todo caso, el humanismo es una forma de positivismo y, como todo pensar del ente, no puede siquiera aproximarse al ser. Pues bien, sin pensar el ser, el nihilismo está servido. Era la tesis del Husserl de "La crisis de las ciencias europeas": las ciencias dejan como está el problema del sentido reduciendo al hombre mismo, obnubilado por el saber de lo 'positum', también a un mero hecho sin entrever ninguna diferencia entre las cosas y el ser humano sometido, como toda la 'empiria', al principio de causalidad que guía el estudio de la naturaleza. Desde aquí, desde esta falta de especificidad del hombre, no cabe fundar una noción fuerte de dignidad. No estamos 
haciendo teoría vacía. No estamos ante una filosofía caprichosa de conceptos y gustosa en aquilatar vocablos para reclamar su sitio en la historia del pensar. Los desastres vividos demuestran que la cultura europea, nacida al albur de la racionalidad, no ha encontrado un pensar del hombre que parapete la barbarie. Nada como el desmoronamiento socio-político del siglo XX para demostrar las consecuencias de un pensar que obvia el ser fijado solo en los entes. La dificultad de la tarea le viene al pensar no por lo complicado del asunto sino por la extrema sencillez con la que la proximidad del ser pasa desapercibida en una sin par confusión con los entes. Esta proximidad del ser para con el hombre, esta vecindad en la que el hombre habita con el ser en su verdad es la que toma forma de lenguaje (Heidegger, 2016, p. 46). Habitando en la vecindad del ser, el ser humano encuentra protección y cobijo en el ser a través del lenguaje que a su vez "es la casa del ser y la morada de la esencia del hombre" (Heidegger, 2016, p. 90). Curiosamente, justo cuando se desentiende el hombre de su proximidad del ser, el lenguaje más que expresión de libertad trastoca su esencia en instrumento de dominio al servicio de las manipulaciones subjetivas.

¿Se podrá ofrecer, entonces, un nuevo sentido a la palabra 'humanismo' tal y como se cuestionaba Beaufret? Quizá no sea necesario. Quizá debamos desconfiar de los 'ismos' porque confunden al pensar, lo degradan a un procedimiento, someten su libertad a un estricto método y cercenan su esencia al reducirlo a un instrumento. La palabra, el lenguaje, sirve a este pensar lógico-conceptual-representativo fijándolo y anquilosándolo en los entes. Entonces, ¿cuándo el lenguaje podrá albergar al ser y concebirse como su casa si más bien sirve al pensar embaucado en los entes? Cuando el lenguaje quede liberado de la palabra, de la palabra en cuanto concepto que tiene la pretensión de someter bajo su yugo toda la realidad, lo veremos enseguida. "En su decir, el pensar sólo lleva al lenguaje la palabra inexpresada del ser" (Heidegger, 2016, p. 91). Por lo tanto, el lenguaje no puede ser pensado ni como conjunto de signos ni como productor o generador de significados, sino que "el lenguaje es el advenimiento del ser mismo que aclara y oculta" (Heidegger, 2016, p. 36). Esta preeminencia de la palabra que a fuerza de insistir en lo dicho olvida el puro decir es el síntoma más evidente y actual de la decadencia hodierna del lenguaje. Y la opinión pública, el decir impersonal que es de todos (con tal de que no sea de nadie, que diría Ortega y Gasset) es la mejor explicación de la degradación en términos de abuso de la palabra en esta era, la nuestra, que es la de la sociedad de la información. Y en mi opinión, de la misma manera que la técnica es la expresión más prolija de la metafísica consumada, la opinión pública lo es también del lenguaje manipulado del 
pensar representativo. Porque, de alguna manera, la opinión pública es una forma vulgar de exacerbar lo que el lenguaje conceptual hace con la realidad: uniformarla. Y al uniformarla, el lenguaje se convierte en un instrumento de dominación. De este modo, parece que el lenguaje tiene una esencia bifronte dependiendo, según lo visto, de cómo se ejerza el cuidado de la palabra, si al servicio de la lógica mediante el seguimiento de la gramática, o como cobijo del ser. La palabra que nace del pensar del ser, al expresar la relación esencial del hombre y el ser, "raras veces tiene algo que decir" (Heidegger, 2016, p. 24). Es la palabra que está siempre por decir. Es la palabra de este tiempo postfilosófico que es, como pensar inicial que se busca, de aspiración prefilosófica. Así que, pensar el humanismo desde el pensar posthumanista exige repetir el pensar acerca del hombre para sostener que la sospecha de lo desapercibido desde el inicio es la verdad de la esencia buscada del ser humano. "¿Se puede seguir llamando humanismo a este pensamiento? Está claro que no, puesto que el humanismo piensa metafísicamente" (Heidegger, 2016, p. 48).

¿Qué significa entonces pensar metafísicamente? Mantenerse en la 'concepción técnica del pensar' que arranca en los inicios del pensamiento lógico-conceptual desde Platón. Esta interpretación técnica subyace a la comprensión teórica del conocimiento que inaugura 'la época de la imagen del mundo', reduciendo la filosofía a teoría del conocimiento, resolviendo la cuestión de la verdad como una mera 'corrección de la mirada', resituando así el problema de la 'aletheia' en su estar en el entendimiento y, haciendo de su justificación como saber frente a las ciencias el tema capital de su ocupación. Pues bien, esta interpretación técnica del pensar que sirve de humus teórico al surgimiento del humanismo abunda en la ocultación de la 'diferencia ontológica' al concebir todo pensar como dirigido hacia los entes en una tarea cuyo éxito final depende de criterios como la exactitud, la calculabilidad y la productividad. Mientras tanto, este pensar olvida la simpleza del ser de cuya verdad depende su propia esencia como ser humano. "Más próximo que lo que está más próximo de todo, el ente, y al mismo tiempo, para el pensar corriente, más lejano que lo que resulta más lejano de todo se encuentra la proximidad misma: la verdad del ser" (Heidegger. 2016, p. 45).

\section{3. "La esencial pobreza del pastor": tesis para un posthumanismo kenótico}

Proponemos a continuación un conjunto de tesis que apuntan las que creo que son las tres posibles direcciones de investigación que se abren desde el posthumanismo kenótico que se ha perfilado en las páginas anteriores. 
La primera tesis es que este posthumanismo debe pensar la esencia del ser humano en cuanto fundada poéticamente. Como se aclara en Einführung in die Metaphysik, qué sea el hombre no lo llegamos a saber por medio de una definición erudita, sino sólo de manera tal que el hombre entra en confrontación con el ente, en tanto que trata de llevarlo a su ser (Heidegger, 1983, p. 153). ¿Qué significa entonces fundar poéticamente? En primer lugar, fundar poéticamente supone "liberarse de la gramática" para acceder a un ámbito de fundamentación radicalmente distinto al del concepto. De esta manera, el tradicional rechazo de la fenomenología a la pretensión de la antropología de ser filosofía primera alcanza aquí un grado de justificación más profundo que la crítica a que un saber positivo pretenda constituirse en scientia omnium rerum. La antropología obvia que lo real es mucho más que lo positum. No es pues suficiente con atender a la verdad como correspondencia entre los conceptos y la realidad, sino a la aletheia por la cual lo patente, lo revelado, lo presente, lo cierto, lo positum... siempre remite a lo latente, a lo ausente, a lo incierto, a lo no pensado. Fundar poéticamente es, entonces, permitir que la verdad que se busca tome forma de desocultamiento, aunque este nunca sea del todo definitivo como asumiendo tanto lo insondable del ser que nunca queda agotado en los entes, como la finitud del pensar que nunca revela definitivamente la realidad como resuelta del todo.

Pero, además, fundar poéticamente es reconocer que sólo el decir poético se ajusta a una realidad como la del ente que es el 'Dasein' entreverada por la historia, constituida por el tiempo, existencialmente abierta y determinada por su propia finitud, lo veremos enseguida. ¿Qué se puede decir de este ente en cuanto 'signo por interpretar'? Que el 'Dasein' es constitutivamente apertura y que cualquier decir sobre él es siempre penúltimo por no agotar nunca una esencia que es, precisamente, inagotable. Sólo el decir poético la funda porque solo la poesía se acerca no a decir, pero sí a evocar esa realidad insondable constituida por ser en su vecindad con el ser. Y por ello también el cuidado, que según la analítica existenciaria desplegada en "Sein und Zeit", era la esencia del 'Dasein' en cuanto "preserse ya en el mundo como ser cabe los entes que nos hacen frente", es una actitud para con el lenguaje, para con la palabra que tiene que albergar la verdad del ser, para el pensar que consiste precisamente en el encuentro por el que el ser llega a ser lenguaje. Pero albergar nunca es colapsar. Por eso el lenguaje, aun siendo la casa del ser, no es una construcción del ser humano para su protección, sino la intemperie en la que el pensar no puede hallar cobijo en una palabra que subsuma lo que de por sí es inefable. El lenguaje de los poetas es ahora, en el tiempo en que el pensar es más meditación que respuesta, el 'Ereignis' en el que se descubre el misterio 
que entre-adviene al hombre y al ser y que, así, aclara al tiempo que oculta. Poetizar es la única manera de encontrarse en y con el misterio del ser que desborda la razón y la palabra. Con el misterio del ser cuyo destino es darse, sin poder darse del todo, en una falta que ha de pensarse, en una presencia de lo ausente que ha de rememorarse. En definitiva, en un reconocimiento de hasta qué punto la presencia del ser para el 'Dasein' "brilla por su ausencia". Fundar poéticamente es, por lo tanto, acceder mediante otro lenguaje ya no instrumental ni subyugador a ese ámbito previo a la determinación metafísica del hombre como sujeto en términos del 'Dasein'. Es el acceso poético a la pura concreción fáctica de la existencia que requiere un quiebro en el pensar, un viraje que cambia la dirección férrea del concepto por la libertad del verso que más que producir la realidad que describe, la sugiere y evoca sin pretensión alguna de fundamentación definitiva. Vivimos absortos de palabras. Todo tiene un nombre y, casi por su propia naturaleza, el lenguaje imprime categorías a la realidad resumiéndola, haciendo pública la experiencia privada, objetivando las vivencias subjetivas etc. Todo decir es un etiquetar que permite comunicar tanto como impide ver la realidad como tal. De hecho, en la observación de las reglas de la gramática se sigue manteniendo presa para el pensar la esencia del hombre. ${ }^{7}$ Es la paradójica transparencia y opacidad de la palabra. La filosofía, como la propia ciencia, ha estado de alguna manera presa de la palabra, sometida a los conceptos que pretenden capturar la realidad y obnubilada por la búsqueda de un lenguaje correspondiente con el mundo que ha de pensar. Frente a esa concepción del lenguaje propia del pensar representativo, fundar poéticamente es reconocer lo infundado de toda realidad poética. Y el hombre lo es, recuérdese que 'dichterisch wohnet der Mensch' (Heidegger, 2001, p. 139), poéticamente habitan los hombres. Porque la poesía, continúa explicando Heidegger en esa conferencia, no puede ser considerada como un sobrevolar lo real, como una especie de fuga idílica de lo actual hacia lo imaginario. Es necesario cambiar el acorde del pensar para descubrir la

7 La tesis de Grassi es que el humanismo que tiene enfrente Heidegger no es la tradición real del humanismo italiano fraguado en torno al valor del lenguaje poético (Bocaccio, Salutati, Landini, Pontano...) sino la lectura que desde Burckhardt o Voigt hasta Cassirer, Gentile y Garin se ha hecho del humanismo como redescubrimiento del hombre y de sus valores inmanentes. Así sí se puede entender que Heidegger tache de antropomorfismo ingenuo toda esa tradición del pensar humanista. Según Grassi, Dante tanto en "De vulgari eloquentia" como en "Convivio" descubre que el poeta es el fundador de la comunidad y que así abre el camino de la historicidad. Por lo tanto, la naturaleza característica del lenguaje poético es la de abrir o hacer patente lo que el lenguaje científico, en cuanto lenguaje artificial, mantiene oculto (Grassi, 2006, p. 10). Es muy interesante la propuesta de Grassi de vincular el análisis heideggeriano a las tesis de Vico en su Ciencia Nueva. Todo ello para fortalecer su idea inicial de que Heidegger malinterpreta la tradición humanista en la que siempre "ha habido una preocupación central por el problema de la primacía del desocultamiento, de la patencia, de aquello en lo que por primera vez puede aparecer el ser ahí histórico" (Grassi, 2006, p. 23). 
esencia del poetizar en la interpelación que el ser humano recibe del lenguaje cambiando el señorío subjetivo que queda impreso en la palabra. Frente a esa esclavitud por la que el lenguaje sirve a la hybris señorial, el poetizar descubre la libertad, esto es, la apertura hacia lo insospechado que escapa a la lógica de la verdad en términos de correspondencia. ${ }^{8} \mathrm{Al}$ poetizar le resulta ajena la concepción de la verdad lógica de la tradición metafísica porque la verdad que acontece en el hablar poético es el desvelamiento de lo oculto que no conlleva tanto la revelación total cuanto el hacerse cargo del ocultamiento. En ese sentido, habita poéticamente el hombre; mora en el lenguaje que le hace estar en la vecindad del ser.

Fundar poéticamente es, por último, existir en lo innominado para dejarse reclamar por el ser revitalizando el valor de la palabra. Por mucho que la esencia del habitar sea el proteger, el lenguaje poético no es ningún modo blindado construido para la propia protección del ser humano. Esa no es la protección del habitar poético pues el lenguaje sigue insistiendo en la intemperie como corresponde a la esencia del 'Dasein'. Es la intemperie de la palabra que rehúsa decir en cuanto dejar por sentado, en cuanto agotar la realidad. La palabra poética es el signo de la inseguridad, de la desprotección. Y es el hombre el que accede al ser por el lenguaje, por este lenguaje. Pero el lenguaje puede tanto aproximarle a la vecindad del ser como establecer una hostilidad para con los entes. Así se destruye la casa. Así habita no-poéticamente el hombre la tierra. La forma primordial de habitar no poéticamente es la de disimular la esencial ausencia de patria (Heimatlosigkeit) del 'Dasein'. Por eso, frente a la palabra que es pura palabrería no está sólo el nihilismo del silencio, que en el fondo se mantiene en las mismas coordenadas del pensar representativo, sino el pensar fundado poéticamente que hace del ser humano, en mi opinión, un oyente del ser. Hablar es una manera de habitar 'poéticamente' con tal de que la palabra dicha pretenda solo decir sencillamente lo complejo de lo insondable del ser que siempre quedará por decir y al que, ante todo, cabe solo escuchar.

La segunda tesis de este posthumanismo consiste en reconocer la esencia del ser humano como estando en camino, el descubrimiento de la finitud y el consiguiente final de los discursos ahistóricos sobre la esencia inmutable del hombre como si estuviera dotado de una naturaleza a prueba del tiempo. Existir no es estar dado de una vez para siempre, sino que implica hacerse,

8 "La verdad no es una característica de la proposición conforme enunciada por un sujeto humano acerca de un objeto y que luego valga no se sabe en qué ámbito, sino que la verdad es ese descubrimiento de lo ente mediante el cual se presenta una apertura" (Heidegger, 2015, p. 161). 
realizarse. "Todo movimiento -en cuanto estar en camino hacia Badisis eis- consiste en un todavía-no-haber-alcanzado su hacia qué (su horizonte) [...] el andar considerado en su carácter ontológico es por principio distinto a lo ya andado" (Heidegger, 2002, p. 72). Este posthumanismo se constituye, así, como filosofía del tránsito que siempre presupone un recorrido que en ningún momento hace desaparecer el origen; un camino que avanza a medida que progresa la capacidad de preguntar "que en lugar de representaciones y conceptos, se pone a prueba como transformación de la relación con el ser" (Heidegger, 2015, p. 171).

Con Platón, se había dado carta de naturaleza a la tradición occidental que anula el permanente in fieri por considerar que la verdad reside en la mirada recta, correcta, dirigida sólo hacia el final del trayecto, obviando que la verdad es un tránsito que no se resuelve nunca, porque es el paso de lo oculto a lo revelado en el que lo oculto se refugia, pero no desaparece en lo desoculto, como había tratado de decir Anaximandro. ${ }^{10}$ El posthumanismo de la kénosis implica pensar la esencia humana desde la contingencia del "mientras" de la vida que envuelve la existencia humana de provisionalidad. "Nosotros mismos somos este "de camino", esta transición, este ni lo uno ni lo otro" (Heidegger, 2017, p. 28). Y esta contingencia del ser 'en camino' es la que explica la 'finitud' del ser humano como el modo fundamental de nuestro ser que, como tal, ha de ser preservada frente a tanto intento por disimularla como el de la metafísica humanista, su consumación en la técnica moderna y su falsa promesa al hombre: "seréis como dioses".

La finitud empieza a formar parte de la esencia del ser del ente que es el 'Dasein' cuando descubre que su sentido, vinculado a la temporalidad, es el futuro en el que acontece la muerte que le adviene. ${ }^{11}$ Esta finitud ya fue barruntada por Kant con su subjetividad constituyente que, según Heidegger se encontraba vertebrada por la nada. De esa manera, la finitud es, a mi modo de ver, la consecuencia más decisiva que se deduce del existenciario fundamental

9 Vivir es "estar en camino". La tarea de vivir es designada así por Heidegger, transformando un concepto que Jaspers había forjado siguiendo a Kierkegaard (Gander, 2006, p. 164).

10 Según Heidegger, en la sentencia de Anaximandro, aparecen dos palabras clave: nacimiento y muerte, que él traduce como provenir y escapar o transcurrir, y que además son parte constitutiva de todo movimiento. La sentencia muestra cómo ya desde antiguo el ser ha sido concebido como devenir. Un devenir este del pensar inicial que no ha sido pensado ni por el concepto de devenir de Hegel o de Nietzsche. En suma, dice Heidegger la sentencia dice que el ser es irrupción de la presencia sin que esto implique necesariamente constancia en la consistencia que persiste, es decir, sin que esto suponga el inicio de la metafísica de la presencia. El provenir, lo que Anaximandro llama génesis, no puede significar el abandono de aquello a partir de lo cual sale a la luz ese provenir. De este modo, el regreso al inicio del pensar es "el regreso hacia el a-partir-de-donde en cuanto plenitud de la irrupción de la presencia” (Heidegger, 2005, p. 154).

11 "El concepto de la finitud está en la base de la problemática de la fundamentación de la metafísica [...] La comprensión del ser es la esencia más íntima de la finitud” (Heidegger, 2013, p. 196). 
del 'Dasein', in der Welt Sein, al permitirnos entender la existencia casi en términos agustinianos de caída (Verfallen) por ser el 'Dasein' geworfener Entwurf. El 'Dasein' es un ser de posibilidades, un ente que es siempre ser posible (Möglichsein), poder ser (Seinkönnen). Por lo tanto, ya desde Ser y Tiempo, la finitud resulta derivada de la concepción de la existencia en este caso porque se entiende desde su esencia proyectiva que enfrenta la muerte, mientras que la finitud de la 'ek-sistencia' del hombre le viene dada ahora, en Carta sobre el humanismo, por su dependencia del ser en cuya verdad habita. Existir no tiene que ver con la penumbra que se adivina en la interpretación existencialista y nihilista que se agota en lo óntico (como ha pretendido Sartre en El existencialismo es un humanismo), sino con la claridad del ente que es estando en el claro del ser desde el que se abre como posibilidad de ser y desde el que descubre la apertura del mundo para sí mismo. Sea como sea, la finitud del 'Dasein' es la más conspicua explicación de que el ser humano no puede explicarse por sí mismo, de que no se agota en sí, con el consiguiente rechazo de todos los discursos antropológicos fraguados en torno a la idea de autonomía del hombre como ser a se. La finitud, entonces, está arraigada en la dependencia del ser humano con respecto al ser y manifestada en su esencia proyectiva y abierta en constante necesidad de ser con los otros hombres y con los otros entes, constituido por la temporalidad del futuro que está siempre adviniendo, y pertrechado de la contingente historicidad que le hace ser estando siempre en camino. Una dependencia que no supone una merma de la autonomía en términos de razón y libertad sino de la autonomía que degeneró en el poder omnímodo y pretencioso responsable de la barbarie vivida y sufrida.

¿Cómo sabe el hombre de su finitud? En la soledad, en el retiro en el que el ser humano alcanza, en la distancia para con el mundo, la proximidad de lo esencial de todas las cosas. A este saberse en la finitud creo que puede denominarse Gelassenheit, serenidad. Heidegger avanza algo esta noción de serenidad cuando rescata alguno de los fundamentos filosóficos de la mística medieval, por ejemplo, el concepto capital de recogimiento (Abgeschiedenheit) o de retraimiento tomado de Eckhart. ${ }^{12}$ Se trata del esfuerzo humano por girarse desde las cosas a su propio interior. Es la reflexión que descubre la pertenencia del alma a Dios a cuya luz todas las cosas aparecen sin la subjetividad prejuiciosa y adulterada del conocimiento humano. ${ }^{13}$ Este giro interior, este

12 Según Baeza (2011), Eckhart es fundamental para entender la coniunctio entre temporalidad y eternidad a través de un radical "adelantarse a la muerte" (Vorlaufen in der Tod).

13 A pesar de que Eckhart se refiere a la relación del hombre con Dios y Heidegger, a la relación del hombre con la naturaleza, según Caputo, 1986. 
recogimiento (colligere) es tanto como el desvanecimiento de uno mismo; es la actitud kenótica de abajamiento por la que el ser humano se hace cargo de su nimiedad y la actitud de quien se encuentra libre respecto de todo lo creado al dejar ser a las cosas (lassen que curiosamente es lo contrario de machen: hacer que exista algo $)^{14}$ sin convertirlas en útiles para sí mismo, sin forzarlas para servir a cualquier patrón subjetivo. Es, en definitiva, la humildad tan relacionada con el concepto de pobreza que es condición de posibilidad del acceso al fundamento. Agustín ya lo había insinuado tanto en su Confesiones como en los Soliloquia: "cuando nada terreno te atraiga ni te deleite, entonces en aquel momento, créeme, verás lo que deseas"15. Hacerse cargo de la propia nada libera de todos los vínculos y esclavitudes con el mundo. Se trata de desprenderse de sí, de renunciar a sí para reconocerse en el interior de uno mismo, en esa conversión mística que supone dejar de lado las cosas. Se trata de resituar la cuestión del hombre para que el subjetivismo epistémico y el egoísmo moral que acontecen comórbidamente resulten mitigados por el descubrimiento de la finitud que desde las primeras obras de Heidegger recibió el nombre de facticidad. ${ }^{16}$

La tercera tesis de este posthumanismo kenótico debe pensar la esencia del hombre vinculada a su tarea pastoral. El hombre no es señor del ente sino pastor del ser. El ser humano es un fragmento del mundo, pero no solo. El hombre tiene mundo y por ello es a la vez señor y siervo del mundo (Heidegger, 2017, p. 226). "Tener mundo" es exactamente lo que diferencia al ser humano de otros entes que también son fragmentos del mundo y que, o "no tienen mundo" (como es el caso de la piedra) o "son pobres de mundo" (como es el caso del animal). Pastor del ser y habitante en la casa del ser le exigen calma, escucha, servicio y espera a lo que el ser encomiende. Por lo tanto, más allá de la literatura humanística, se abre en esta época posthumanística la necesidad de una ascesis derivada de la meditación que corresponde a la interpelación del ser al hombre cuyo efecto a largo plazo es el desarme de la subjetividad que ejerce toda su potencia con(tra) el ente. "La esencia del hombre consiste en ser más que el mero hombre entendido como ser vivo dotado de razón. El más no debe tomarse aquí como una mera adición [...] el más significa de

14 La libertad, escribe Heidegger en De la esencia de la verdad, se desvela como dejar ser a lo ente. Teniendo en cuenta que dejar ser no implica desinterés o indiferencia, sino todo lo contrario. "Dejar ser es el meterse en lo ente [...] meterse en lo abierto y en su apertura" (Heidegger, 2015, p. 160)

15 "Itaque, quando fueris talis, ut nihil te prorsus terrenorum delectect, mihi crede, eodem momento, eodem puncto temporis videbis quod cupis" (Sol. 1.14.24).

16 "Con su facticidad el Dasein ya no tenía nada a sus espaldas: ser o no ser era únicamente su asunto, su "cuidado" justamente, en comparación con cuyo poderío no era capaz de ser otra cosa" (Blumenberg, 2011, p. 161). 
modo más originario y de modo más esencial en su esencia”. El hombre no pierde nada en este menos, sino que "gana la esencial pobreza del pastor" (Heidegger, 2016, p. 60). ¿Qué es entonces esta pobreza?

Tomamos aquí algunas reflexiones de la conferencia Die Armut, impartida por Heidegger el 27 de junio de 1945 para un pequeño grupo en la casa forestal del castillo Wildenstein de Hausen. En este texto se intenta comentar los versos de Hölderlin "Entre nosotros, todo se concentra en lo espiritual, nos hemos vuelto pobres para llegar a ser ricos", por medio de los cuales el poeta ensaya los periodos de la historia occidental. Lo que de aquí es importante para nuestro objetivo es la sinonimia de lo espiritual (Das Geistige) con lo sublime, como si de la religión fuera necesario salvar el momento trascendente. En palabras de Hölderlin: "Ni él solo ni los objetos que lo rodean pueden hacer sentir al hombre que existe algo más que un funcionamiento mecánico, que hay un espíritu, un dios en el mundo [...] una relación sublime que lo eleva por encima de la necesidad" (Hölderlin, 1967, p. 647). Esta relación en la que queda determinado lo espiritual es de otra índole a la relación metafísica sujeto-objeto siempre determinada por la urgencia que tenemos de que los propios objetos palien las carencias que provoca en nosotros la necesidad. Lo sublime (erhaben) no lo es solo por estar por encima de la relación sujetoobjeto sino que hace relación a la altura a la que se refiere la dignidad del ser humano. "Lo alto de esa altura de lo sublime es en sí la profundidad" (Heidegger, 2006, p. 103). Porque, en definitiva, la sublimidad es la relación del ser con el hombre (die Beziehung des Seyns zum Menschen) en la que el propio ser humano encuentra refugio y patria.

Desde aquí, Heidegger explica qué significa la pobreza que, en el sentido habitual, refiere al carecer de lo necesario (Nötingen). Sin embargo, ¿de qué depende la esencia de la pobreza? Según nuestro autor, ser verdaderamente pobre significa ser de tal manera que sólo se carezca de lo no-necesario (Unnötige) (Heidegger, 2006, p. 107), invirtiendo la cuestión de la esencia de la pobreza como corresponde a un pensar de otra manera. Cuando en términos materiales hablamos de pobreza, nos referimos a carencia. Esa carencia que se echa de menos lo es en relación a la superabundancia de cosas, de bienes superfluos que Heidegger caracteriza como de 'no-necesarios'. En este sentido, cuando alguien, en este contexto del pensar moderno-técnico se refiere a lo necesario, se está refiriendo a lo necesario respecto de la necesidad apremiante, respecto a la necesidad de cosas (Not). ${ }^{17}$ Una necesidad impuesta, debe ser cubierta" (Heidegger, 2015, p. 200). 
coactiva como la llega a denominar Heidegger (Zwingende), porque la esencia de esta necesidad es el haber generado en nosotros la obligación de satisfacerla sin más. Frente a esta necesidad que obliga, que esclaviza y determina la tarea humana como una permanente satisfacción de una necesidad que cada vez es más apremiante y más grande, se vislumbra para el pensar pensante la necesidad de algo necesario que no coacciona, sino más bien al contrario, la necesidad de algo que libera. ¿Cómo algo que es necesario puede a la vez ser liberador? Porque se sustrae al esquema representativo que subyuga todo objeto a la potestad incontestable del sujeto. Porque deja ser lo que es protegiendo su esencia sin doblegarla, sin someterla ${ }^{18}$. Lo que permite la pobreza es descubrir que aquello de lo que se carece, en el fondo, no es una pertenencia propia estrictamente hablando porque de lo que carecemos es de aquello que no necesitamos para ser. Lo que hace libre de la libertad es precisamente el producir la inversión de esa necesidad apremiante, de esa necesidad que sitúa al hombre en una dinámica de necesidades crecientes. En mi opinión, se puede sencillamente captar la intención del pensar de Heidegger distinguiendo las necesidades coactivas de la necesidad que acontece en la libertad, dejando que la necesidad y la libertad, en cuanto opuestos tradicionalmente entendidos por la metafísica, se piensen como complementarios (Heidegger, 2006, p. 109). Y no se trata del aparente equilibrio kantiano entre necesidad y libertad sino de un giro más profundo por el que la libertad es la necesidad en la medida en que lo que libera es lo no-necesario, esto es, lo que está fuera del radio de acción de las necesidades coactivas. El pobre es el que carece de lo no-necesario que, ahora en el contexto del pensar no representativo, nunca podemos tenerlo, porque su propia esencia se sustrae al ser objetivo de las cosas y, por lo tanto, se resiste a ser objetivado, a ser cosificado. Por eso, más que tenerlo, eso nonecesario nos tiene. Y teniéndonos, eso no-necesario nos da libertad. Por eso, lo no-necesario es lo liberador. Y eso que, por un lado es lo más coactivo por blindar su impronta en cada ente que tiene que ser, es la liberación por permitir y dejar ser al ente en el espacio, en el claro en el que sobre todo el ser humano tiene que 'ek-sistir'.

Por eso ser pobre es ser rico. Porque la pobreza permite al hombre avistar otra necesidad que la de la riqueza material oculta aviesamente mientras genera necesidades que satisfacer en un vacío nunca del todo colmado. La pobreza es riqueza porque es la consciencia de la sobreabundancia del ser

18 "Liberar significa original y propiamente preservar, dejar a algo reposar en su propia esencia protegiéndolo. Pero proteger es retener la esencia en el cobijo donde sólo permanece si se le permite retornar al cobijo de su propia esencia" (Heidegger, 2006, p. 109). 
(Überflu $\beta$ des Seins) que nos falta en una ausencia que, ahora en la pobreza, sentimos presente. En definitiva, ser pobre sigue siendo una carencia, pero no la carencia de cosas que a su vez impiden pensar la necesidad esencial, sino la oportunidad para poder pensar la carencia de aquello que se retrae al pensar entitativo, para poder ser conscientes de la necesidad del ser. Sólo ser conscientes, rememorar este olvido, esta carencia, esta necesidad, ya vuelve rico al ser humano por saberse existiendo a la sombra del ser, por recordarle la contingencia de su esencia y la insustancialidad de las necesidades apremiantes del mundo. ${ }^{19}$ "En esta calma inquieta reposa la serenidad habituada a poner fin a todo cuanto atañe a la necesidad apremiante" (Heidegger, 2006, p. 115). La pobreza es otro modo de hablar de la kénosis que andábamos buscando para este posthumanismo que afronta el vacío de un tiempo, el nuestro, lleno de cosas, instigador de una oquedad existencial que con nada se rellena totalmente sino solo en la parcialidad de la satisfacción momentánea de necesidades generadas ante demandas crecientes de insatisfacción constante. $\mathrm{Y}$ ese es el movimiento circular y sin salida en el que está instalado el ser humano actual que no puede generar otra cosa que aburrimiento (Langeweile). ${ }^{20}$

El caso es que nunca se vuelve uno pobre del todo. El ser humano no es nunca bastante pobre. Siempre hay algún signo de riqueza que impide dejar hueco a la presencia (aunque sólo sea en forma de recuerdo) de la ausencia, a la necesidad de lo no-necesario; siempre hay alguna esclavitud que no deja campar a sus anchas a la libertad. Pero pensar la pobreza, dejar que el pensar medite, sólo es posible cuando el ser humano se concentre en lo espiritual, cuando el ser humano se descubra congregado por el ser para habitar en su claro y a su luz.

La esencia de la pobreza es el carecer definido como el 'faltar los entes' que abre la posibilidad de un habitar distinto "en una relación más viva con aquello que lo rodea". La pobreza presenta una fuerte relación con la angustia, con el pensar y con la serenidad (Candiloro, 2014, p. 40). Esa pobreza que nos permite descubrir la mundanidad del mundo precisamente en su 'falta de mundo' (al modo como la falta de utilidad del útil nos permitía conocer

19 "El peligro propio de la necesidad apremiante y de los tiempos de indigencia está en que el destello mismo de la necesidad apremiante impide que sea verdaderamente experimentada la esencia de esta necesidad y que sea percibido a partir de esta esencia el signo que llama a poner fin a la necesidad apremiante" (Heidegger, 2006, p. 115).

20 Heidegger ha dedicado bastantes páginas al aburrimiento, especialmente en el curso de Friburgo del semestre de invierno de 1929-1939 Die Grundbegriffe der Metaphysik entendiéndolo como el oculto temple de ánimo fundamental de las interpretaciones filosófico culturales de nuestra interpretación. El aburrimiento se presenta fenomenológicamente en tres formas: el ser aburrido por algo, el aburrirse con algo y el aburrimiento profundo explicado como el 'uno se aburre'. 
la esencia de lo Zeitlichkeit en Ser y Tiempo) hace posible que el ser humano vuelva a los entes. Volver a los entes (lejos ya de la huida de ellos en una posición teórica que reniega de lo cotidiano, pero lejos también de un abandono en los mismos característico de la existencia impropia) supone reconocer el lugar de los entes como correlativos de una 'ek-sistencia' fraguada como apertura del 'Dasein' al mundo.

Pensar la esencia del hombre no es pensar la dignidad en términos de un ascenso hacia una realidad suprema, sino hacerlo desde el descenso hacia la indigencia de la existencia humana. Y esta es la clave del pensar kenótico que sustenta la deconstrucción del humanismo que hace Heidegger: tomar en consideración lo humano como la esencia determinada por la 'ek-sistencia' pobre en cuanto indigente al estar en continua salida hacia fuera como pura exterioridad, en cuanto pura apertura a los entes, en cuanto facticidad constituida por la finitud que resulta vehiculada por la temporalidad, en cuanto ente que merece ser pensado descubriendo su profunda dependencia del ser con la consiguiente despedida de la conciencia trascendental husserliana que nihil indigeat ad existendum. Es la pobreza del ser humano que el pensar descubre cuando recuerda la determinación animal que ante todo el hombre es, recobrando así el valor y el respeto por la naturaleza en la que el hombre tiene que habitar de otro modo a como lo ha hecho hasta ahora. Permanecer en la vecindad del ser es síntoma de la dignidad del hombre que descubre su riqueza justo en la pobreza resultante de 'no entregarse al ente'; que descubre su grandeza en la aceptación de su pequeñez en la que el ser humano ya no destaca por su señorío y sobre los entes a los que, al final, termina abandonándose, sino por su estancia en el ser.

\section{Conclusiones}

Queda para trabajos posteriores establecer las correspondencias entre la crítica al humanismo de Heidegger y la estela de rechazo a la antropología como filosofía primera que había iniciado la fenomenología de Husserl. De modo que, como habría apuntado este último en la conferencia impartida en Berlin titulada Phänomenologie und Antropologie, lo sobreentendido se vuelve un gran enigma para la fenomenología. El humanismo es, como la antropología, 'poco' para ser llamado filosofía. Otra cosa es si la sustitución del reinado del hombre por el reinado del ser, en palabras de Glover (2007, p. 30), permitirá al pensar ocuparse del hombre o si el giro heideggeriano dará al traste con el saber popular y comprensible sobre el ser humano a cambio de sustituirlo por un pensar que ha virado $y$, por no tener ya objeto, se hace tan incomprensible 
y pretencioso (Adorno, 2007, p. 425) que siquiera tiene ya dirección alguna. Es casi la tesis de Levinas: volver al ser para recuperar la esencia del hombre olvidada por la tradición metafísica y de tan mala fortuna para la humanidad conlleva olvidarse del hombre real y concreto cuya conciencia de finitud le sobreviene por el reconocimiento de la trascendencia del otro. Cierto es que un humanismo esencialista es de factura violenta y sirve a la complicada relación entre los hombres en términos de guerra. Preciso es devolver a la filosofía primera la raíz ética en la que el rostro del otro descubre la alteridad donde se encuentran los cimientos de una fraternidad que no se puede decir so pena de poderse traicionar. En Heidegger, la fenomenología creía haber encontrado ya el aldabonazo filosófico suficiente como para recordar el valor de lo concreto, de lo práctico en el sentido de lo que es previo a toda teoría y, por lo tanto, en este caso, del hombre real desatendido por el humanismo. Sin embargo, Levinas cree que el discurso heideggeriano no es suficiente para huir de la metafísica violenta y apropiadora e inaugurar así la filosofía primera "que deja al otro pasar a primer plano, que cede ante él en lugar de combatirlo" (Levinas, 2006, p. 203).

En todo caso, es mérito de Heidegger haber insistido en el daño moral que determinadas lecturas del humanismo occidental podrían generar en el espíritu humano que no es capaz ya de reconocerse en su nuda facticidad y, por lo tanto, que no es capaz de operar el descenso de ese pensar de la kénosis justamente opuesto a la tan glorificada hybris de la razón. Y, cómo no, es mérito el haber desmantelado el interés del humanismo en resolver de una vez por todas lo que de por sí es ya siempre enigmático: "si el hombre es un tránsito, una dirección, una tormenta que barre nuestro planeta, un retorno o un hastío para los dioses" (Heidegger, 2016, p. 30). ${ }^{21}$

\section{Referencias}

AGUSTÍN DE HIPONA, "Soliloquios” en Obras Completas I, Madrid, BAC, 2002 ADORNO, T. H. “Dialéctica Negativa: La jerga de la autenticidad”. Madrid: Akal, 2007. BAEZA, R. "Heidegger y el pensamiento medieval". Temas Medievales, Vol. 19, pp. 115-136, 2011.

BLUMENBERG, H. "Descripción del ser humano". Madrid: FCE, 2011.

CANDILORO, H. "Pobreza de mundo. Una indagación sobre el humanismo y el mundo de la vida en el pensamiento de M. Heidegger". Revista de Filosofia, Vol. 70, pp. 27-44, 2014. 
CAPUTO, J. D. “The mystical element in Heidegger's thought". New York: Fordham University Press, 1986.

CHOZA, J. "Lectura de la Carta sobre el humanismo". Themata. Revista de Filosofia, Vol. 32, pp. 37-82, 2004.

DUQUE, F. "En torno al humanismo". Madrid: Tecnos, 2006.

GANDER, H. H. "La fenomenología hermenéutica del vivir fáctico de Heidegger". (pp. 139-172). In: DUQUE, F. (ed.). Heidegger: Sendas que vienen. Madrid: Círculo de Bellas Artes, 2006.

GLOVER, J. "Humanidad e inhumanidad. Para una historia moral del s. XX". Barcelona: Cátedra, 2007.

GRASSI, E. "Heidegger y el problema del humanismo". Barcelona: Anthropos, 2006. GRONDIN, J. "Heidegger und Agustin. Zur hermeneutischen Warheit". In: Richter, E. Die Frage nach der Warheit. Frankfurt: Vittorio Klostermann, 2010.

HEIDEGGER, M. "Los conceptos fundamentales de la metafísica: mundo, finitud, soledad". Madrid: Alianza, 2017.

. "Interpretaciones fenomenológicas sobre Aristóteles". Madrid: Trotta, 2002 . "Carta sobre el humanismo". Madrid: Alianza, 2016.

"Einführung in die Metaphysik". Vittorio Klostermann: Frankfurt, 1983.

. "Poéticamente habita el hombre". (pp. 139-152). In: Conferencias y artículos. Barcelona: Ediciones del Serbal, 2001.

. "Para qué poetas". (pp. 199-238). In: Caminos de bosque. Madrid: Alianza, 2015. . "Beiträge zur Philosophie (Vom Ereignis)". Frankfurt: Vittorio Klostermann, 1989.

. "Nietzsche". Barcelona: Ariel, 2013.

" "Conceptos Fundamentales." Madrid: Alianza, 2005.

. "Kant y el problema de la metafísica". México: FCE, 2013.

. "La pobreza". Madrid: Amorrortu, 2006.

. "De la esencia de la verdad". (pp. 151-173). In: Hitos. Madrid: Alianza, 2015.

HÖLDERLIN, F., "Oeuvres". Paris: Bibliothèque de la Pléiade, 1967

HUSSERL, E. "Phänomenologie und Antropologie". Philosophy and phenomenological research, 2/1, pp. 1-14, 1941.

LEVINAS, E. "Los imprevistos de la historia”. Salamanca: Sígueme, 2006.

LÖWITH, K. "Heidegger pensador de un tiempo indigente". Madrid: FCE, 2006.

SLOTERDIJK, P. “Sin salvación”. Madrid: Akal, 2011. 